\title{
CARPAL TUNNEL SYNDROME
}

\section{Long-term nerve conduction studies in 261 hands}

\author{
Dante Guilherme Velasco Hardoim', Guilherme Bueno de Oliveira', João Aris Kouyoumdjian²
}

\begin{abstract}
Objective: To compare a long-term carpal tunnel syndrome (CTS) on nerve conduction studies (NCS) in hands treated non-surgically. Method: We retrospectively selected 261 symptomatic CTS hands (166 patients), all of them confirmed by NCS. In all cases, at least 2 NCS were performed in an interval greater than 12 months. Cases with associated polyneuropathy were excluded. NCS parameters for CTS electrodiagnosis included a sensory conduction velocity $(\mathrm{SCV}) \leq 46.6 \mathrm{~m} / \mathrm{s}$ (wrist to index finger, $14 \mathrm{~cm}$ ) and distal motor latency (DML) $\geq 4.25 \mathrm{~ms}$ (wrist to APB, $8 \mathrm{~cm}$ ). Results: $92.8 \%$ were women; mean age was 49 years (20-76); the mean interval between NCS was 47 months (12-150). In the first exam, the median sensory nerve action potential (SNAP) and the compound action muscular potential were absent in $9.8 \%$ and $1.9 \%$, respectively. In the second/ last exam, SCV worsened in $54.2 \%$, remained unchanged in $11.6 \%$ and improved in $34.2 \%$. SNAP amplitude worsened in $57.7 \%$, remained unchanged in $13.1 \%$ and improved in $29.2 \%$. DML worsened in $52.9 \%$, remained unchanged in $7.6 \%$ and improved in $39.5 \%$. Overall, NCS parameters worsened in $54.9 \%$, improved in $34.3 \%$ and remained unchanged in $10.8 \%$. Conclusion: Long-term changing in NCS of CTS hands apparently were not related to clinical symptomatology and could lead to some difficulty in clinical correlation and prognosis. Aging, male gender and absent SNAP were more related to NCS worsening, regardless the mean interval time between the NCS.
\end{abstract}

KEY WORDS: carpal tunnel syndrome, median nerve, nerve conduction studies, compressive neuropathy, longterm electrophysiological evaluation.

\section{Sindrome do tunel do carpo: estudo evolutivo de parâmetros de condução nervoso em 261 mãos}

Resumo - Objetivo: Comparar evolutivamente parâmetros de condução nervosa (CN) na síndrome do túnel do carpo (STC) em mãos não submetidas à cirurgia. Método: Foram selecionadas retrospectivamente 261 mãos (166 pacientes) com STC sintomática confirmadas por $\mathrm{CN}$ e que posteriormente realizaram exame controle com intervalo $\geq 12$ meses; foram excluídos casos com polineuropatia. Os parâmetros eletrodiagnósticos anormais foram: velocidade de condução sensitiva (VCS) $\leq 46,6 \mathrm{~m} / \mathrm{s}$, segmento pulso-II dedo, e latência distal motora (LDM) $\geq 4,25 \mathrm{~ms}$, segmento pulso-APB $(8 \mathrm{~cm}$ ). Resultados: $92,8 \%$ eram mulheres; a média de idade foi 49 anos (20-76); o tempo médio entre os exames foi 47 meses (12-150); 9,8\% e 1,9\% não apresentaram potenciais de ação do nervo sensitivo (PANS) e potenciais de ação muscular compostos, no primeiro exame. No segundo exame a VCS piorou em $54,2 \%$, ficou igual em $11,6 \%$ e melhorou em $34,2 \%$; a amplitude do PANS piorou em $57,7 \%$, ficou igual em $13,1 \%$ e melhorou em $29,2 \%$; a LDM piorou em $52,9 \%$, ficou igual em $7,6 \%$ e melhorou em 39,5\%. Incluindo todos os parâmetros eletrofisiológicos, houve piora em $54,9 \%$, melhora em $34,3 \%$ e permaneceram sem alterações 10,8\%. Conclusão: As anormalidades da CN na STC podem oscilar ao longo do tempo e aparentemente independem da sintomatologia clínica, dificultando a correlação e prognóstico; idade mais avançada, sexo masculino e PANS ausentes no primeiro exame foram as variáveis que tiveram menor percentual de melhora evolutiva, independentemente do intervalo entre os exames.

PALAVRAS-CHAVE: síndrome do túnel do carpo, nervo mediano, condução nervosa: neuropatia compressiva, evolução eletrofisiológica de longo prazo.

\footnotetext{
Neuromuscular Investigation Laboratory, Department of Neurological Sciences, Faculdade de Medicina de São José do Rio Preto, São José do Rio Preto SP, Brazil (FAMERP); ${ }^{1} \mathrm{MD}$, Medical Undergraduate Student (Undergraduate Research Project); ${ }^{2} \mathrm{MD}$, PhD, Professor of Neurology. Financial support: Bolsa de Iniciação Científica (BIC) from FAMERP.
}

Received 18 July 2008, received in final form 22 October 2008. Accepted 27 November 2008.

Dr. João Aris Kouyoumdjian - Rua Luiz Antônio da Silveira 1661 - 15025-020 São José do Rio Preto SP - Brasil. E-mail: jaris@famerp.br 
Carpal tunnel syndrome (CTS) refers to the most common compressive neuropathy in humans. Median nerve is compressed when pass through carpal tunnel about 2 $\mathrm{cm}$ distal to the wrist groove together with nine tendons: Flexor Digitorum Superficialis (4), Flexor Digitorum Profundus (4) and Flexor Pollicis Longus (1) forearm muscles'. In Rochester, Minnesota, USA, the incidence of CTS was progressively higher from each period of five years from 1961-65 till 1975-80 (88, 102, 100 and 125/100,000 persons/year, respectively), and it occurs more frequently in females between 40 and 60 years of age with a peak incidence at 45 to 54 years ${ }^{2}$. In Holland, the estimated minimal prevalence of CTS was $0.6 \%$ for male and $5.8 \%$ for female ${ }^{3}$. The most common CTS symptoms include paresthesias and numbness in the median sensory distribution, mainly at night, awakening patients, and, also in the morning and in same maintaining hand griping posture. CTS usually follow a three-phase evolution: first, with slight intermittent sensory symptoms; second, with persistent sensory symptomatology; and third, with persistent sensory negative symptoms and tenar atrophy ${ }^{4}$.

CTS diagnosis is most commonly confirmed by nerve conduction studies (NCS), gold-standard for this condition. One can find focal abnormality on median nerve with increase distal latencies after sensory and motor NCS from wrist to finger or wrist to Abductor Pollicis Brevis muscle, respectively. The CTS symptomatology duration (months or years) is variable, and it was not strictly related to the electrophysiological median nerve severity ${ }^{1,4-6}$.

The long-term evolution of CTS is not stereotyped, and its precise natural history continues to be not completely understood ${ }^{7}$. There are still many controversy da$\mathrm{ta}^{8}$; many patients develop progressive symptoms deterioration, while others remain long periods without symptoms changing and even have complete spontaneous remission. Also, it also can worsen after many years of remission, can run a seasonal symptomatology and, less frequently, can develop acute symptoms. Young patients, unilateral symptoms and negative Phalen test seem to have a better prognosis. Overall, spontaneous improvement may occur in up to $21 \%$ of CTS patients. In a study, $77.6 \%$ had referred "cure" and 13.6\% "much better" from CTS symptoms after surgery", although, paradoxically the subjective surgical benefit has been reduced in some reports ${ }^{8}$.

A long-term (more than a year) CTS nerve conduction parameters in symptomatic patients with hands treated non-surgically can be very useful to better understand its natural history. In a multicenter Italian study ${ }^{10}$ with a follow-up ranging from 10 to 15 months from first to second evaluation, untreated patients had $27 \%$, neurophysiologic improvement, $57 \%$ remained stationary, and only $16 \%$ experienced worsening. In a small group of non-surgically patients, Resende et al." showed electrophysiological improvement in $8 / 20$, worsening in $2 / 20$ and unchanged in $10 / 20$ hands after a follow-up ranging from 4 to 9 years. Ortiz-Corredor et al. ${ }^{12}$ studying 132 patients without any kind of treatment in a 2-year follow-up, found electrophysiological (NCS) deterioration in $7.6 \%$, improvement in $25 \%$ and unchanged in $67.4 \%$.

The objective of the present study is to compare NCS from median nerve sensory and motor parameters in a sample of non-surgically CTS patients in whom two NCS were performed in a 12-month interval of from each other at least. The findings would be useful to better understand the natural evolution of CTS.

\section{METHOD}

Out of 13,178 electroneuromyogram database performed by one author (JAK) from 1989 to 2006 (18 years), 3,833 cases were selected with CTS electrodiagnosis. From those, another filter was added to select cases that had undergone 2 exams at least in an interval equal or greater than 12 months. In cases with more than 2 exams just the first and the last one were used. Cases surgically treated, cases with electrophysiological evidence of peripheral nervous system abnormalities (e.g., polyneuropathy), and those in which the nerve conduction parameters could not be completely compared were excluded.

After all exclusions, 166 patients were selected for data analysis. They presented typical clinical CTS symptomatology according to the American Association of Neuromuscular and Electrodiagnostic Medicine ${ }^{13-15}$ : (1) numbness and paraesthesia in 2 median innervated fingers at least; (2) pain could be present, but not as an isolated complaint; (3) intermittent symptomatology in the first stage; (4) worsening symptoms at night, in some positions or after repetitive hand action; (5) symptoms improved by shaking hands, changing hands position or by splint device.

In the first exam, the electrophysiological parameters used for CTS electrodiagnosis were the following: median nerve sensory distal latency equal or greater than $3.0 \mathrm{~ms}$ (onset-measured), wrist to index finger (antidromic), $14 \mathrm{~cm}$ fixed distance; median nerve sensory conduction velocity (CV) equal or less than $46.6 \mathrm{~m} / \mathrm{s}$ in the same segment; median nerve motor distal latency equal or greater than $4.25 \mathrm{~ms}$, wrist to Abductor Pollicis Brevis muscle, $8 \mathrm{~cm}$ fixed distance. According to these parameters, 261 hands were selected, 148 right and 113 left.

Descriptive statistics was used for mean and standard deviation of the electrophysiological parameters. The local ethics committee (CEP-FAMERP) approved the protocol.

\section{RESULTS}

The mean age of the 166 patients in the first exam was $49 \pm 11$ years, ranging from 20 to 76 years. The mean age in the second/last exam was $51 \pm 11$ years, ranging from 24 to 80 years. A hundred fifty four patients $(92.8 \%)$ were fe- 
Table 1. CTS hands without treatment: outcome of the median nerve conduction parameters between 2 NCSs (mean interval: 49 months).

\begin{tabular}{lcccc}
\hline & $\begin{array}{c}\text { SNAP } \\
\text { DSL }\end{array}$ & $\begin{array}{c}\text { SNAP } \\
\text { Amplitude }\end{array}$ & $\begin{array}{c}\text { CMAP } \\
\text { MDL }\end{array}$ & Total \\
\hline Hands & 260 & 260 & 210 & \\
Worsen & $54.2 \%$ & $57.7 \%$ & $52.9 \%$ & $54.9 \%$ \\
Unchanged & $11.6 \%$ & $13.1 \%$ & $7.6 \%$ & $10.8 \%$ \\
Improved & $34.2 \%$ & $29.2 \%$ & $39.5 \%$ & $34.3 \%$ \\
\hline
\end{tabular}

CTS, carpal tunnel syndrome; NCSs, nerve conduction studies; DSL, distal sensory latency; SNAP, sensory nerve action potential; MDL, motor distal latency; CMAP, compound muscular action potential.

male and 12 patients $(7.2 \%)$ male. The mean time from the first to the second/last exam was $47 \pm 31$ months, ranging from 12 to 150 months.

A comparison of median sensory and motor nerve conduction electrophysiological parameters between first and second/last exams were done in 260 and 210 CTS hands respectively. Sensory nerve action potential (SNAP) and compound motor action potential (CMAP) were not obtained in $9.8 \%$ and $1.9 \%$ respectively.

The comparison of the valid electrophysiological parameters between the first and the last exam as percentage of worsen, unchanged and improved is shown on Table 1. Overall, $34.3 \%$ had electrophysiological improvement being $34.2 \%$ from median SNAP distal latency, $29.2 \%$ from median SNAP amplitude and 39.5\% from median CMAP distal latency.

The gradation (severity) of the CTS electrophysiological parameters was performed according to the sensory median nerve $\mathrm{CV}$, wrist to index finger, in the first exam. Three groups comprised: mild (CV between 46.6 and 40.0 $\mathrm{m} / \mathrm{s})$, moderate $(<40.0 \mathrm{~m} / \mathrm{s})$ and severe (absent of SNAPs). Table 2 shows the percentage of worsen, unchanged and improved outcome in the last exam according to the severity (mild, moderate and severe) in the first exam. The variables age, gender and interval between exams were also added. Mild CTS hands in the first exam had higher percentage of improvement when compared to severe ones ( $38.3 \%$ vs $25.0 \%$ ), irrespective to the interval between the exams. Only $2.4 \%$ of mild CTS hands in the first exam became severe in the last; in contrast, $22.2 \%$ of moderate CTS hands in the first exam became severe in the last. Male gender had a higher percentage of severe CTS hands in the first exam ( $15.4 \%$ vs $6.9 \%$ ).

Table 3 shows the relationship between initial severity and outcome to worsen, unchanged and improved when variables mean age and interval from the first to the last exam were considered. The outcome of mild or moderate cases apparently were not related to age or interval (duration) between the 2 exams. Mild cases that became severe had a less mean age than those cases that went to improvement or unchange. Severe initial cases that had not improved were older than those that had improvement ( 55.2 vs 45.5 years); the mean interval between exams was shorter if cases were severe at the beginning.

\section{DISCUSSION}

The electrophysiological parameters of NCS in CTS can oscillate along the years and apparently are not related to the clinical symptomatology leading to some

Table 2. CTS hands without treatment: NCS severity in the first exam vs gender, age, interval between exams and outcome of the electrophysiological parameters in the last exam.

\begin{tabular}{lccccccccc}
\hline & Hands & $\mathrm{M}$ & $\mathrm{F}$ & Interval* $^{*}$ & Age* $^{*}$ & Improved & Unchanged & Worsen & Inexcitable \\
\hline Mild & 162 & $6.9 \%$ & $93.1 \%$ & $45.0(30.0) \mathrm{m}$ & $47.2(11.2)$ & $38.3 \%$ & $8.6 \%$ & $53.1 \%$ & $2.4 \%$ \\
Moderate & 81 & $11.3 \%$ & $88.7 \%$ & $49.5(31.3) \mathrm{m}$ & $48.8(10.2)$ & $34.6 \%$ & $4.9 \%$ & $60.5 \%$ & $22.2 \%$ \\
Severe & 16 & $15.4 \%$ & $84.6 \%$ & $37.0(19.0) \mathrm{m}$ & $52.7(13.0)$ & $25.0 \%$ & $75.0 \%$ & - & $75.0 \%$ \\
\hline
\end{tabular}

CTS, carpal tunnel syndrome; NCS, nerve conduction study; M, male; F, female; m, months; *mean (standard-deviation); **included in the worsen group.

Table 3. CTS hands without treatment: NCS severity in the first exam (mild, moderate or severe), outcome (worsen, unchanged or improved) in the last exam and variables age and interval between exams.

\begin{tabular}{|c|c|c|c|c|c|}
\hline Group & Variable & Improved* & Unchanged* & Worsen* & Inexcitable** \\
\hline \multirow[t]{2}{*}{ Mild } & Age & 45.9 (11.2) & $50.6(15.1)$ & 47.3 (10.7) & $39.7(13.2)$ \\
\hline & Interval & $43.8(30.1)$ & $50.4(35.7)$ & $46.0(29.6)$ & $63.5(49.4)$ \\
\hline \multirow[t]{2}{*}{ Moderate } & Age & $49.1(10.3)$ & $47.1(7.7)$ & $48.8(9.5)$ & $49.2(7.9)$ \\
\hline & Interval & 49.5 (31.7) & $51.3(36.6)$ & $50.3(31.1)$ & $68.2(35.4)$ \\
\hline \multirow[t]{2}{*}{ Severe } & Age & $45.5(13.4)$ & $55.2(12.5)$ & & \\
\hline & Interval & 36.7 (8.5) & 37.9 (21.1) & & \\
\hline
\end{tabular}

CTS, carpal tunnel syndrome; NCS, nerve conduction study; ${ }^{*}$ months (mean and standard deviation); **included in the worsen group. 
difficulties to effective clinical correlation and also the prognosis.

There are few studies about CTS natural evolution. CTS patient's follow-up without surgery can reveal a significant improvement on median nerve sensory and motor conduction studies ${ }^{7}$, even though in a less proportion compared to the cases surgically treated. Usually the evolution of CTS symptoms in longitudinal studies does not run through in parallel to the abnormalities in median $\mathrm{NCS}^{16}$.

In the present series, $34.3 \%$ of all electrodiagnosticated symptomatic CTS cases have improved the nerve conduction parameters in the second/last exam after a mean time of 47 months; $10.8 \%$ remained unchanged, and $54.9 \%$ worsened. It should be emphasized that median nerve sensory CV, amplitude of the SNAP and the motor distal latency have the same percents of variation, either improvement, unchanged and worsening in the second/last exam. The variables advanced age, male gender and absent SNAPs were more frequently associated to a lower degree of improvement, regardless the interval between exams. The outcome of mild or moderate initial cases apparently were not related to age or duration of the disease. Mild cases that became severe were younger than those that went to improvement or unchanged. In contrast, severe initial cases that had not improved were older than those that had improvement.

Distinct from our findings, Ortiz-Corredor et al. ${ }^{12}$ found that only $7.6 \%$ of the 132 CTS patients without any kind of treatment, either conservative or surgical, went to electrophysiological deterioration in a 2 year follow-up, and the authors suggested that most patients diagnosed with CTS remain stable or even improved over time. Padua et al. ${ }^{10}$ found a little bit more electrophysiological worsening $(16 \%)$ in a 10 to 15 months follow-up, but still much less than our findings (54.9\%) after a mean follow-up of 47 months. On the other hand, they found less improvement than our findings ( $27 \%$ versus $34.3 \%$, and most of their cases remained stationary (57\% versus $10.8 \%$ ). In spite of these findings from other series, in which a significant percentage of CTS patients had no change in their clinical and electrophysiological condition over 2 years at least, and even improved spontaneously without treatment, they found the percentage of electrophysiological worsening much lower than our cases, maybe because of the inclusion criteria allowing cases with normal NCS and also a short follow-up compared to our series.

Similar to other authors, Karsidag et al. ${ }^{17}$ have reported that the most significant electrophysiological improvement occurred after surgery, but pointed out a variable percent of cases with spontaneous improvement. Kouyoumdjian et al. ${ }^{9}$ findings added some additional difficul- ties to the understanding of CTS natural history. They concluded that, in spite of cases with short duration of symptoms had a greater improvement to conservative treatment, the majority of cases that remain symptomatic to the same conservative treatment had mild median nerve conduction abnormalities. Yet, they found that conservative treatment was more frequently indicated to older patients, probably because they could be more tolerant to CTS symptoms. The severity of nerve conduction parameters could not be useful to indicate the choice of treatment and, also, they are not related to duration of symptomatology in all cases. Padua et al. ${ }^{10}$ added more conflicting issues with the findings that CTS patients with severe neurophysiologic classes had more improvement than moderate ( $46 \%$ versus $29 \%$ ), and the latter more than the mild ones ( $29 \%$ versus $12 \%$ ). These findings echo the assertive of Robinson and $\mathrm{Kliot}^{18}$ that emphasizes the useless of electrophysiological CTS grading except for distinction between axon loss and demyelination. Resende et al. ${ }^{11}$ reported that $40 \%$ of 20 CTS hands without surgery presented an electrophysiological improvement in a 4 to 9 year follow-up; in this period $50 \%$ remained unchanged and only $10 \%$ deteriorated. In spite of this sample might be biased because of the small number of patients (12 cases and 20 hands), these data confirmed that we do not know precisely the natural history and the factors that could predict the best prognosis without surgery or even any kind of conservative treatment.

According to Bland ${ }^{8,19}$, a complete cure without any kind of treatment, either by use of splints, steroids infiltration or surgery, is reached in 20 to $30 \%$ of CTS cases. Yet according Bland $^{19}$, 37\% of CTS patients had improved using splints and $70 \%$ with steroids infiltration even though the time symptoms relief was variable - from $92 \%$ relapsing in 2 years to $50 \%$ improvement in 7 years.

In conclusion, our data showed that, firstly, $34.3 \%$ of CTS patients had an electrophysiological improvement without treatment in a long-time follow-up; secondly, the natural history remained not well known; thirdly, the correlation between severity and temporal evolution of the electrophysiological parameters to clinical symptomatology is imprecise; and, fourthly, cases with absent median SNAP, elderly and male gender presented a less percentage of electrophysiological improvement.

\section{REFERENCES}

1. Kouyoumdjian JA. Síndrome do túnel do carpo. Aspectos atuais. Arq Neuropsiquiatr 1999;57:504-512.

2. Stevens JC, Sun S, Beard CM, O'Fallon WM, Kurland LT. Carpal tunnel syndrome in Rochester, Minnesota, 1961 to 1980. Neurology 1988;38:134-138

3. de Krom MC, Knipschild PG, Kester AD, Thijs CT, Boekkooi PF, Spaans F. Carpal tunnel syndrome: prevalence in the general population. J Clin Epidemiol 1992;45:373-376. 
4. Dawson DM, Hallett M, Wilbourn AJ. Entrapment neuropathies. Philadelphia, New York: Lippincott-Raven, 1999.

5. Kouyoumdjian JA. Síndrome do túnel do carpo. Aspectos clínico-epidemiológicos em 668 casos. Arq Neuropsiquiatr 1999;57:202-207.

6. Kouyoumdjian JA. Carpal tunnel syndrome: age, nerve conduction severity and duration of symptomatology. Arq Neuropsiquiatr 1999;57:382-386

7. Todnem K, Lundemo G. Median nerve recovery in carpal tunnel syndrome. Muscle Nerve 2000;23:1555-1560.

8. Bland JDP. Treatment of carpal tunnel syndrome - Special invited review. Muscle Nerve 2007;36:167-171.

9. Kouyoumdjian JA, Morita MPA, Molina AFP, et al. Long-term outcomes of symptomatic electrodiagnosed carpal tunnel syndrome. Arq Neuropsiquiatr 2003;61:194-198.

10. Padua L, Padua R, Lo Monaco M, Aprile I, Tonali P. Multiperspective assessment of carpal tunnel syndrome: a multicenter study. Italian CTS Study Group. Neurology 1999;53:1654-1659.

11. Resende LA, Tahara A, Fonseca RG, Sardenberg T. The natural history of carpal tunnel syndrome: a study of 20 hands evaluated 4 to 9 years after initial diagnosis. Electromyogr Clin Neurophysiol 2003;43: 301-304.

12. Ortiz-Corredor F, Enríquez F, Diáz-Ruíz J, Calambas N. Natural evolution of carpal tunnel syndrome in untreated patients. Clinical Neurophysiol 2008;119:1373-1378.
13. Jablecki CK, Andary MT, So YT, Wilkins DE, Williams FH. Literature review of the usefulness of nerve conduction studies and electromyography for the evaluation of patients with carpal tunnel syndrome. AAEM Quality Assurance Committee. Muscle Nerve 1993;16:1392-1414.

14. Practice parameter for electrodiagnostic studies in carpal tunnel syndrome: summary statement. American Association of Electrodiagnostic Medicine, American Academy of Neurology, American Academy of Physical Medicine and Rehabilitation. Muscle Nerve 1993;16: 1390-1391.

15. Practice parameter for carpal tunnel syndrome (summary statement) Report of the Quality Standards Subcommittee of the American Academy of Neurology. Neurology 1993;43:2406-2409.

16. Nathan PA, Keniston RC, Myers LD, Meadows KD, Lockwood RS. Nat ural history of median nerve sensory conduction in industry: relationship to symptoms and carpal tunnel syndrome in 558 hands over 11 years. Muscle Nerve 1998;21:711-721.

17. Karsidag S, Sahin S, Karsidag SH, Ayalp S. Long term and frequent electrophysiological observation in carpal tunnel syndrome. Eura Medicophys 2006;42:1-6.

18. Robinson L, Kliot M. Stop using arbitrary grading schemes in carpal tunnel syndrome. Muscle Nerve 2008;37:804.

19. Bland JDP. Carpal tunnel syndrome: clinical review. Br Med J 2007 335:343-346. 